\title{
Evidence of Chemical Reaction in Binary Blends of Polycarbonate and a Semi-Flexible Liquid Crystal Polymer
}

\author{
H. Hakemi
}

Plastic Liquid Crystal Technology, Via Lambro 80, 20846 Macherio (MB), Italy

\begin{abstract}
In this study, we provide the experimental results of the binary blends of a semi-flexible nematic liquid crystal polymer (LCP1) and polycarbonate (PC) within their phase diagram. The LCP1/PC blends were investigated by Differential Scanning Calorimetry (DSC), Optical Microscopy (OM), Wide-angle X-Ray Diffraction (WXRD), Fourier Transfer Infrared (FTIR), Gel Permeation Chromatography (GPC), and Nuclear Magnetic Resonance (NMR) techniques and observed the evidence of chemical reaction between LCP1 and PC in their heat-treated blends possibly by transesterification mechanism.
\end{abstract}

Keywords: Liquid crystal polymer, polycarbonate, binary blend, chemical reaction, transesterification.

\section{INTRODUCTION}

Liquid Crystal Polymers (LCP) exhibit a highly ordered structure in both the melt and solid states. It can replace such materials as ceramics, metals, composites, and other plastics because of its outstanding strength at extreme temperatures and resistance to virtually all chemicals, weathering, radiation, and burning. LCPs have high melt flow and fast setup which allow them to be molded into large, heavy-walled parts as well as thin-walled components [1-4].

The composite materials with LCP for use in engineering applications should satisfy the following requirements: (i) to consist of at least two physically distinct and mechanically separable materials called matrix and reinforcing component; (ii) to prepare by admixing of the above components and (iii) the composite to possess several properties being superior to that of the individual components [5].

Among the three basic groups of macrocomposites, nano-composites and molecularcomposites the LCP-containing composites can be considered the closest example of molecular composites. Under their molecular structure and conformation, the LCPs tend to form in situ, during processing, with very fine fibers having similar or better reinforcing efficiency as compared to that of conventional inorganic fibers [6].

*Address correspondence to this author at the Plastic Liquid Crystal Technology, Via Lambro 80, 20846 Macherio (MB), Italy;

E-mail: hassanalihakemi@gmail.com
A substantial amount of work has been performed in the area of LCP composites. They possess some important advantages over the conventional fiberreinforced systems: single-step formation, e.g. during the injection molding of the part; improved mechanical integrity of the material; and very good mechanical properties. The inherently high strength and stiffness of the LCPs not only improve the mechanical properties of the resulting blend, but the processing is also free from problems associated with conventional short-fiber composites such as fiber breakage. wear of the equipment, and increase in viscosity [7-10].

Although the basic structural and self-reinforcing criteria of LCPs have been well developed, the optimization of blending and processing conditions to achieve desirable mechanical and rheological properties of their composites with commercial thermoplastics (TP) is still an open field of research. The partial crystalline state of LCPs imparts these plastics with many unique properties such as toughness, exceptional strength, chemical resistance, and high temperature. In addition, the two melting points of thermotropic nematic LCPs offer a broader processing range for these unique polymers. Over the years, based on new potential applications in other fields, such as actuators, organic photovoltaic, renewable energy, and new macromolecular architectures [11-15], a marked shift in the development of new LCPs has been noticed.

Whereas the technology and engineering of LCPreinforced thermoplastics (TP) have been rather well developed, the knowledge of structure-property relations for optimization of processing and prediction of the mechanical properties of LCP/TP composites are 
still far from being complete. The available literature on the mechanical mixing of binary LCP blends with aliphatic-aromatic and wholly aromatic moieties has shown either a matrix compatibility [16-19] or complete immiscibility and phase separation of the components [20-21].

While many macroscopic properties of LCPs are extremely advantageous, thermoplastic polymer blends with LCPs have also been studied extensively as processing aids and reinforcement. There has been a rich literature on the blends of rigid LCPs, such as Vectra-A, Vectra-B, Xydar, and X7G, with commercial thermoplastics including polycarbonate (PC), polystyrene (PS), polyvinyl chloride (PVC), polyethylene (PE), poly-tetra-fluoro-ethylene (PTFE) and polypropylene (PP), which distinguish themselves from standard thermoplastics because of their better flow state during processing. Because of growing interests in applications of LCPs as a processing aid and reinforcement of engineering plastics, the need for the prediction of properties and mechanical behaviour of these high-performance composites has entered a new phase of research and development.

However, it has been shown that the miscibility of LCP blends is a major obstacle in their applications, and introducing some kind of interaction between LCP and flexible-coil polymers have been necessary to improve the miscibility of the two polymers. In this respect, the choice of LCP's chemical structure in blends with flexible chain thermoplastic polymers has been shown to involve chemical reactions. [22-26] Consequently, the thermotropic LCPs with flexible spacers and relatively low melting temperatures could provide some advantages compared to rigid LCPs, such as lower processing temperatures and better compatibility with flexible thermoplastics.

Concerning LCP blends with PC, there exist some scientific literature including studies on various rigid and semi-rigid LCP additives, compatibilizers, and processing aids [27-44], exhibiting chemical reactions, including transesterification [45-49]. In addition, other studies indicated that amorphous PC can be induced to crystallization by the synergistic action of LCP reactive compatibilizer [47], and transesterification in in-situ PC/aromatic-LCP blends exhibited increased compatibility consistent with improvements in mechanical property parameters of the blends [48]. However, by minimizing transesterification in PC/flexible-LCP blends, the tensile modulus of the blend was improved [49].
In the present study, to confirm the occurrence of chemical interaction in LCP and thermoplastic composites for industrial application, we utilized six various characterization techniques (DSC, OM, WXRD, GPC, FTIR, and NMR) and studied the heat-treated blends of a low molecular weight semi-flexible liquid crystal polymer (LCP1) with commercial polycarbonate (PC) at various concentrations. The experimental results of heat-treated blends with all techniques confirmed the miscibility of the two incompatible polymers due to chemical reactions.

\section{EXPERIMENTAL}

\subsection{Materials}

The Polycarbonate (PC) material was Sinvet-301 (EniChem) with a glass transition of $\mathrm{Tg}=154^{\circ} \mathrm{C}$ and was used as received. The LCP material was a semiflexible nematic liquid crystal co-polyester referred to as $\mathrm{SBH} 1$ in the previous works [50-53] and it is codified as LCP1 in this study.

The semi-flexible co-polyester LCP1 was synthesized by melt poly-condensation of mixtures of 4,4'-di acetoxy biphenyl (DBP), sebacic acid (SA), and 4-acetoxybenzoic acid (HBA), resulting in the synthesis of copolymer LCP1 with the following chemical structures and compositions:

\begin{tabular}{|c|c|c|}
\hline $\begin{array}{c}-\left(-\mathrm{O}-\mathrm{C}_{6} \mathrm{H}_{4}-\mathrm{C}_{6} \mathrm{H}_{4}-\mathrm{O}-\left(-\mathrm{OC}-(\mathrm{CH})_{2}\right)_{8}-\mathrm{CO}-\right. \\
)-(\mathrm{DBP})\end{array}$ & \begin{tabular}{c}
$-(\mathrm{SA})$ \\
\hline $25 \%$
\end{tabular} & $\begin{array}{c}\left.-\mathrm{O}-\mathrm{C}_{6} \mathrm{H}_{4}-\mathrm{CO}-\right)- \\
(\mathrm{HBA})\end{array}$ \\
\hline
\end{tabular}

The crystal-nematic transition $\left(\mathrm{T}_{\mathrm{KN}}\right)$ of LCP1 was $221{ }^{\circ} \mathrm{C}$ and its nematic-isotropic $\left(\mathrm{T}_{\mathrm{NI}}\right)$ transition was estimated to be above $400{ }^{\circ} \mathrm{C}$ and could not be properly determined due to decomposition of LCP1 at around $350{ }^{\circ} \mathrm{C}$. The LCP1/PC blends were made by direct mixing of the powders of the two components. The mixing and heat treatment of the blends were performed in Brabender with 10/90, 25/75, 50/50, and $70 / 30$ LCP1/PC weight ratios below $\left(215{ }^{\circ} \mathrm{C}\right)$ and above $\left(257^{\circ} \mathrm{C}\right)$ the $T_{K N}$ of LCP1 followed by direct heat cycling in the DSC pans within $50-300{ }^{\circ} \mathrm{C}$ temperature range until there was no change in the transition temperatures.

\subsection{Methods}

We utilized various characterization methods, including Differential Scanning Calorimetry (DSC), Optical Microscopy (OM), Wide-Angle X-Ray Diffraction 
(WXRD)), Gel Permiation Chromatography (GPC), Fourier Transfer Infra-Red (FTIR), and Nuclear Magnetic Resonance (NMR) spectroscopy in the study of LCP1/PC blends. The detailed descriptions of these methods and techniques are as follows

The DSC method was utilized to measure the transition temperatures and $T_{K N}$ transition enthalpies of pure materials and their binary blends. The DSC measurements were carried out on 10-20 mg samples utilizing a Perkin-Elmer DSC-7 instrument at a heating rate of $20^{\circ} \mathrm{C} / \mathrm{min}$ rate. The binary LCP blends were carried out in a DSC pan by direct weighing and mixing of the components and through repeated heating and cooling cycles (usually 3-4 times) until no further changes were observed in the transition temperatures of the blends.

The OM measurements by a Leitz-Wetzaler polarizing microscope equipped with a Linkam THM600 hot-stage and TMS90 temperature control units were utilized to determine the texture of the materials. After the completion of DSC measurements, the same mixtures were used to determine the transition temperatures with the OM method. All OM in heating and cooling modes of $5-80{ }^{\circ} \mathrm{C} / \mathrm{min}$ rates under a nitrogen atmosphere.

The WXRD studies of the powder samples were performed by a wide-angle Philips X-Ray Powder Goniometer. All XRD spectra were obtained at room temperature during 2-3 hours of exposure with a $\mathrm{Cu}-\mathrm{Ka}$ radiation source.

The Waters Associates GPC instrument was utilized to determine the molecular weights of $P C$ and LCP1/PC blends. The semi-quantitative measurements of the samples at a concentration of $0.2 \%(\mathrm{w} / \mathrm{v})$ in THF were carried out using a tetrahydrofuran (THF) mobile phase with UV-254 nm light detector.

The FTIR spectra were obtained using a PerkinElmer 1760 spectrometer and the measurements were carried out on both films and powders of single component and blends where all data analysis were accomplished after 9 spectra scans.

The NMR spectroscopy of the samples solutions in chloroform was performed by a Bruker AC-200 spectrometer using TMS as an internal reference. For each sample, both ${ }^{1} \mathrm{H}$ and ${ }^{13} \mathrm{C}$ spectra were obtained. In the case of LCP1, which is not soluble in chloroform, the NMR measurement was carried out in pentafluoro phenol (PFP) solution on a Bruker CXP-300 spectrometer.

\section{RESULTS \& DISCUSSION}

The experimental results presented in this study mainly focus on the qualitative presentation of a chemical reaction between LCP1 and PC in their blends. Further in-depth understanding of the specific nature and type of such molecular interactions depends on some Physico-chemical conditions that require a further systematic investigation, which is beyond the context of the present study.

\subsection{DSC Results}

Based on DSC calorimetric method, we measured the transition temperatures and enthalpies of pure LCP1, PC, and their blends LCP1/PC at 10/90, 25/75. $50 / 50,75 / 25(\mathrm{w} / \mathrm{w} \%)$ concentrations. The glass $\left(T_{\mathrm{g}}\right)$ and crystal-nematic $\left(T_{K N}\right)$ transition temperatures of the phase diagram of LCP1/PC blends are presented in Figure 1. The blends were prepared in a DSC pan by direct weighing of the components and the complete mixing was obtained after 3-4 heating-cooling cycles where no further change in their DSC thermograms was obtained.

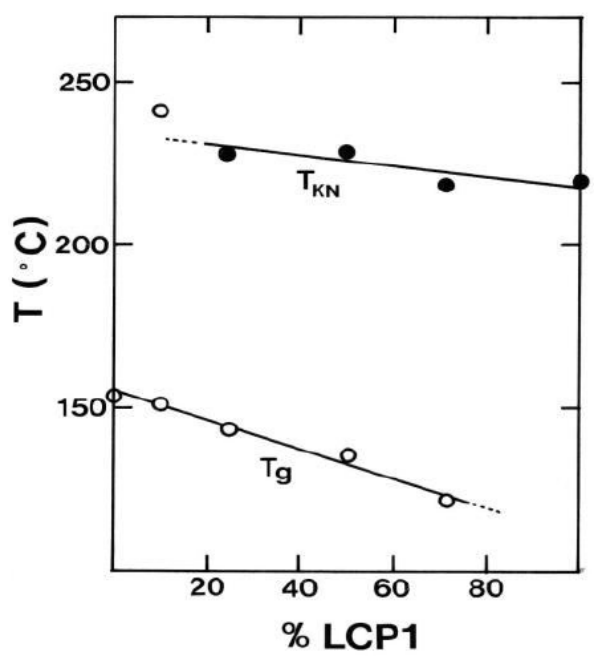

Figure 1: The phase diagram of LCP1/PC blends showing the $T_{K N}$ and $T_{g}$ transition temperatures obtained by the DSC method.

Examples of DSC thermograms of pure components and three LCP1/PC blends are shown in Figure 2, where we found that below the $20 \%$ of LCP1 composition, the blends consist of the primarily onephase region, where the two polymers were completely miscible or interactive. This effect is due to the disappearance of the $T_{K N}$ transition of LCP1. 
Above the 20\% LCP1 composition, the blends exhibited two-phase regions, exhibiting the individual $T_{g}$ and $T_{K N}$ transitions of PC and LCP1, respectively. Also according to Figure 2, by increasing the LCP1 composition in the blend the excess amount of LCP1 becomes evident by the increase of the peak intensity of $T_{K N}$ transition.

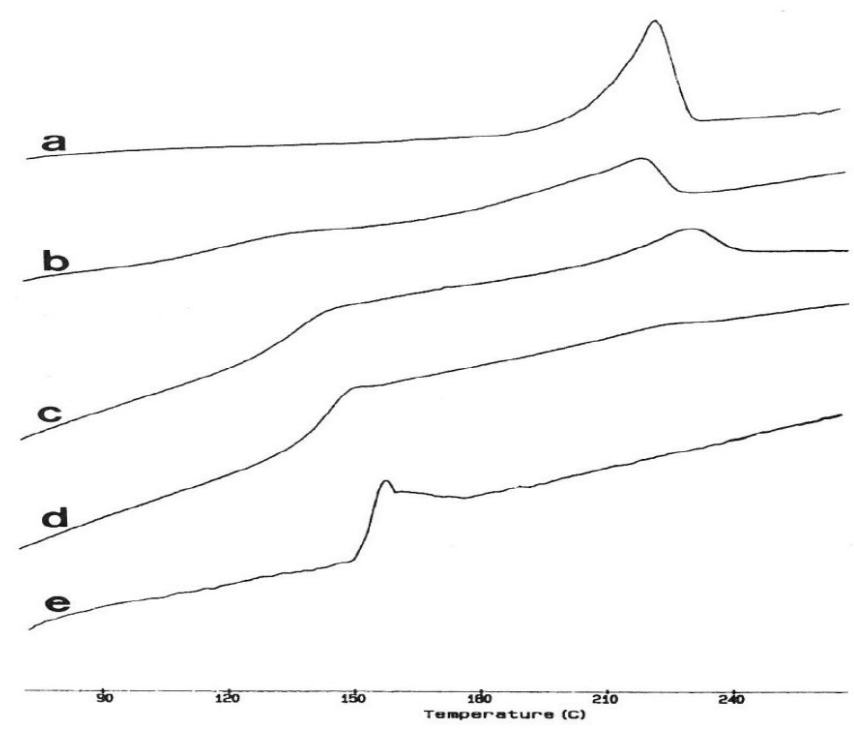

Figure 2: The DSC thermograms of a) pure LCP1, and LCP1/PC blends at b) $25 / 75$, c) $50 / 50$ and d) $75 / 25$ weight ratios, and e) pure $\mathrm{PC}$ at $20 \mathrm{deg} / \mathrm{min}$ heating rate.

This is also evident in the phase diagram of Figure 3, that by increasing the $T_{K N}$ transition enthalpy $\left(\Delta \mathrm{H}_{\mathrm{KN}}\right)$ of LCP1 as a function of its composition, which manifests the contribution of the crystalline structure of LCP1 into the blends. In addition to the behavior of the thermal transition in the phase diagram (Figure 2), there are two other observations that deserve an explanation. The first observation is the linear decrease $\mathrm{T}_{\mathrm{g}}$ of PC by increasing the LCP1 composition, which according to the miscibility rule can occur only if LCP1 has also a $T_{g}$ below that of PC.

Although we have not observed a $T_{g}$ transition for LCP1, the possibility that its glass transition is below that of $\mathrm{PC}$ could not be ruled out. In the phase diagram of Figure 1, one could deduce a $T_{g}=60^{\circ} \mathrm{C}$ for LCP1 by a simple extrapolation to pure LCP1. A similar rationale for $T_{g}$ of LCP1 could be also explained by the molecular weight reduction of PC due to chemical reaction with LCP1. We observed a reduction in the molecular weight of the PC-enriched phase by GPC technique, which will be discussed later in the corresponding section.

The occurrence of chemical reaction in LCP1/PC blends, probably by transesterification mechanism, is evident by the increase in $T_{K N}$ transition of LCP1 by reduction of its content in the phase diagram (Figure 1). This effect, which is in contrast to the partial miscibility concept, could be a result of an increase in the molecular weight of the LCP1-enriched phase or due to its subsequent interaction with $\mathrm{PC}$.

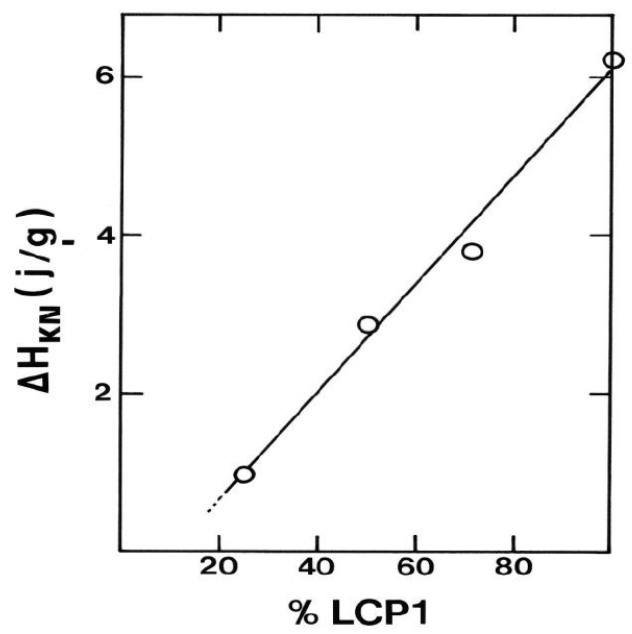

Figure 3: The crystal-nematic $\left(T_{K N}\right)$ transition enthalpies of LCP1/PC blends as a function of LCP1 composition. At blow the $20 \%$ LCP1composition, the $\mathrm{T}_{\mathrm{KN}}$ transition was not observed.

A further indication of chemical interactions between LCP1 and PC is achieved by heat treatment of the blends by preparing 4.0 grams of $50 / 50$ mechanical mixture of LCP1 and PC components and heating in the vacuum oven at $250{ }^{\circ} \mathrm{C}$ for 6 hours. The blended sample was then dissolved in $\mathrm{CH}_{2} \mathrm{Cl}_{2}$ solvent and refluxed with the Kumagawa method for around 10 hours at $40{ }^{\circ} \mathrm{C}$. The weight of recovered insoluble residue was 1.7 grams and that of the soluble portion was 2.3 grams. This indicated that around $29 \%$ of LCP1 has remained in the solution and $21 \%$ remained in the residue. In Figure 4 we present the DSC thermograms of the blend after heat treatment (Figure 4a), $\mathrm{CH}_{2} \mathrm{Cl}_{2}$ soluble portion (Figure $4 \mathbf{b}$ ), and $\mathrm{CH}_{2} \mathrm{Cl}_{2}$ insoluble residue (Figure 4c). The heat-treated blend exhibits a decrease in $\mathrm{T}_{\mathrm{g}}$ of $\mathrm{PC}$ from $154^{\circ} \mathrm{C}$ to $138^{\circ} \mathrm{C}$ and an increase of $\mathrm{T}_{\mathrm{KN}}$ of LCP1 from $221^{\circ} \mathrm{C}$ to $241^{\circ} \mathrm{C}$. The soluble part (Figure $\mathbf{4 b}$ ), which consisted mainly of $\mathrm{PC}$, showed a further reduction of $\mathrm{T}_{\mathrm{g}}$ to $132^{\circ} \mathrm{C}$, whereas the LCP1 residue (Figure 4c) exhibited a single $T_{K N}$ at $241^{\circ} \mathrm{C}$.

The DSC results of the heat-treated LCP1/PC blend by itself indicate the apparent miscibility of the blend is due to chemical interaction and its degree depends on the temperature and time of heat treatment. Note that based on differences in their chemical structures, it is 


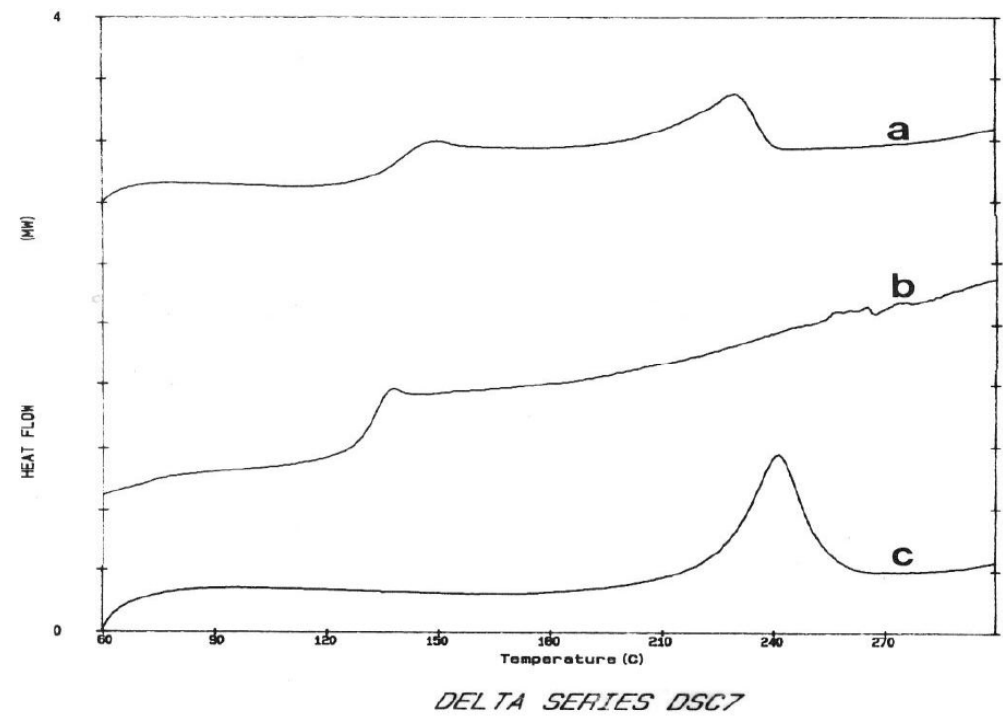

Figure 4: DSC thermograms of 50/50 LCP1/PC blend a) after heat treatment, b) soluble portion in $\mathrm{CH}_{2} \mathrm{Cl}_{2}$ and c) insoluble portion in $\mathrm{CH}_{2} \mathrm{Cl}_{2}$, at $20 \mathrm{deg} / \mathrm{min}$ heating rate.

not expected that PC and LCP1 be miscible in the first place. As we will see in the following sections, the reaction between the two polymers leads to a significant decrease in the molecular weight of PC and the formation of chemical bonds between PC and the remaining fractioned LCP1 molecules.

\subsection{OM Results}

All the studied blend samples with DSC were also subjected to $\mathrm{OM}$ analysis. Although not presented here, the OM results, in agreement with DSC measurements, confirmed the formation of complete compatibility of up to around $20 \%$ LCP 1 content and a two-phase region at higher LCP1 compositions. The two-phase regime consisted of a PC-enriched glass phase and an LCP1-enriched crystalline structure. Above $T_{g}$, the glass phase melted to an amorphous state and above $T_{K N}$ the crystal structure melted to a nematic phase.

In addition to these obvious textural behaviors, we found that below $T_{g}$, both heat-treated PC-enriched and LCP1-enriched blends exhibit birefringent glassy textures. Examples of these glass textures are shown in the micrographs of Figure 5, which indicate that the birefringence is due to the inherent birefringence of the LCP1 matrix.

\subsection{WXRD Results}

In agreement with DSC and OM methods, the WXRD studies of LCP1/PC blends were not only in favor of compatibility but also were in accord with the possibility of chemical interaction between $P C$ and LCP1 components. In Figure 6, we present the WXRD
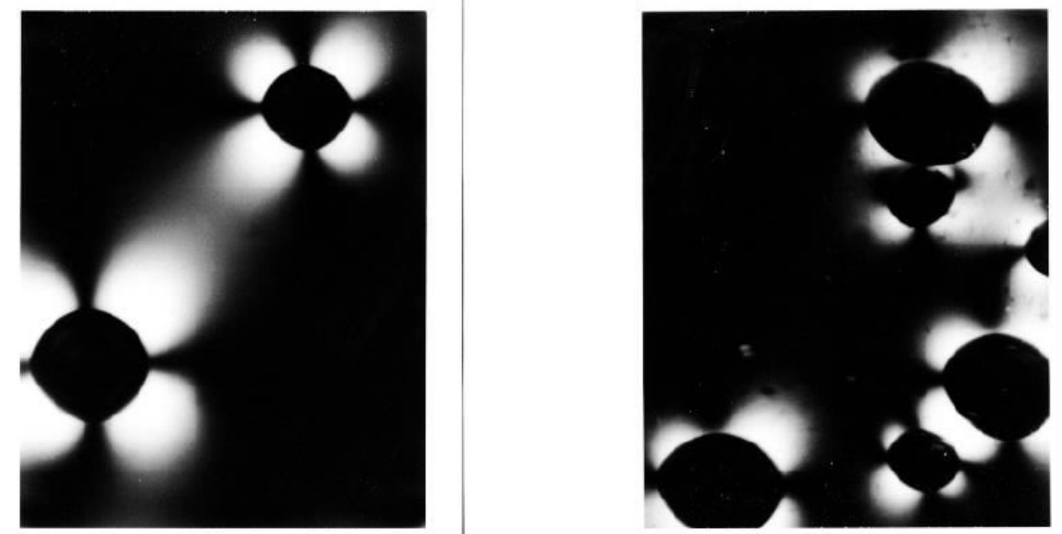

Figure 5: The OM micrographs of birefringent phases of (left) PC-enriched and (right) LCP1-enriched blends under crossed polarization at room temperature. 
spectra of a heat-treated LC1/PC (10/90) blend as a function of treatment time. Figure $\mathbf{6 a}$ is from the original pressed powder blend exhibiting a broad reflection of amorphous PC (centered at $2 q=17.0 \mathrm{deg}$ ) and $a$ reflection of crystalline LCP1 (centered at $2 \theta \mathrm{q}=20.5$ deg).

The diffraction pattern of this sample after subsequent heat treatments at $260{ }^{\circ} \mathrm{C}$ after 2, 5, and 15 minutes are presented in Figures $\mathbf{6 b}-\mathbf{d}$, respectively. The results indicate a gradual decrease $(\mathbf{6 b}-\mathbf{c})$ and disappearance $(\mathbf{6 d})$ of LCP1 crystal diffraction after heat treatment. Referring to Figure $\mathbf{6}$, it should be noted that, the disappearance of LCP1 crystal reflection is accompanied by further broadening of the PC reflection spectrum. These two coupled effects point out more favorably to the occurrence of a chemical reaction than the miscibility of the LCP1 and $P C$. Because of the two polymers were miscible in the solid-state, one should expect to observe the sharpening of PC reflection. Consequently, according to WXRD data, the reduction and subsequent disappearance of crystal reflection of LCP1 in the heattreated blend is not a result of the loss of its crystalline order through miscibility but is due to the chemical interaction between the two polymers under heat treatment.

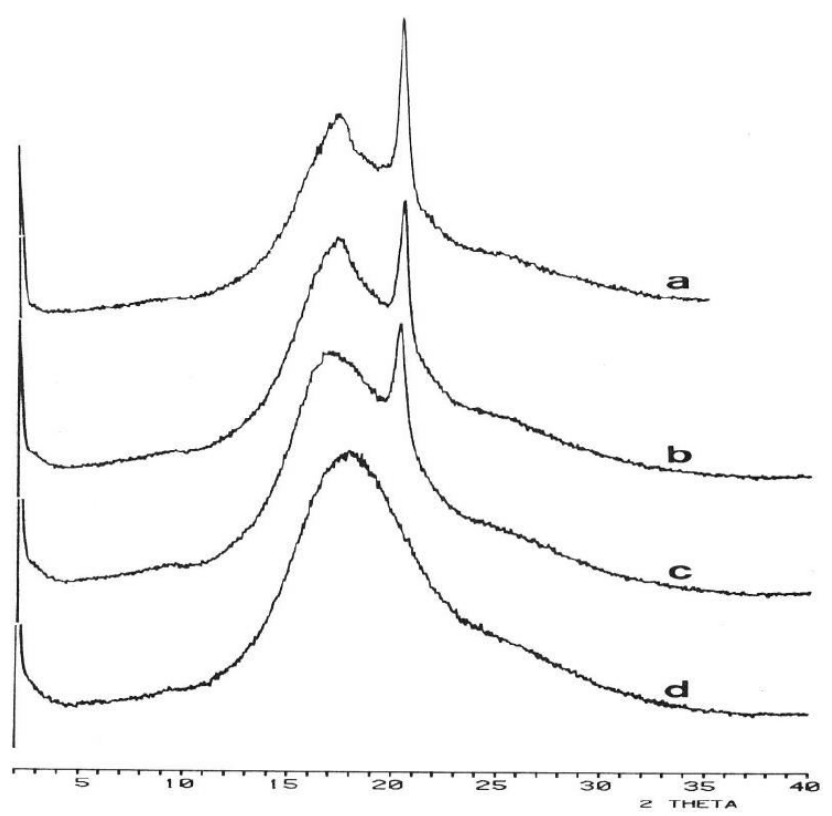

Figure 6: WXRD spectra of 10/90 LCP1/PC blend a) before heat-treatment and after heat-treatment in b) 2.0 , c) 5.0 and d) 15 minutes at $260{ }^{\circ} \mathrm{C}$ under hot press.

\subsection{GPC Results}

The GPC chromatograms of LCP1/PC blends were studied to obtain semi-quantitative knowledge of the number of species and the range of their molecular weight dispersion after heat treatment. In the present study, we only measured the relative molecular weight dispersion of a blend obtained from the soluble portion of a 90/10 LCP1/PC blend treated in a vacuum oven (see Figure $\mathbf{4 b}$ ). The chromatogram of this sample was compared with that of pure PC to study the effect of heat treatment on the molecular weight of PC. Both pure PC and LCP1/PC blends were dissolved in THF at a low concentration of $0.2 \mathrm{w} / \mathrm{v}$ and separately injected in the GPC column. The mobile phase was THF and the retention time was calibrated against Toluene.

The results as presented in Figures $7 \mathbf{a}$ and $\mathbf{7 b}$, respectively, indicate that the $\mathrm{PC}$-enriched portion of the blend (Figure 7a) has a substantially lower molecular weight than pure PC (Figure $7 b$ ). We can deduce two criteria from the GPC data of Figure 7. Firstly, from the larger retention time of the blend $(\mathrm{t}=35.8 \mathrm{~min})$ than that of $\mathrm{PC}(\mathrm{t}=34.2 \mathrm{~min})$ and secondly, from higher sensitivity of LCP1/PC blend concerning PC. Note that the peak sensitivity of blend is an indication of an increase in the number of end-chain functional groups, such as carboxyl and hydroxyl groups. The increase in the number of functional groups in the blend must be due to the reaction between the fractionated LCP1 and PC chains. It should be noted that until now, none of the utilized methods, including the FTIR and NMR that will be discussed later, indicate any evidence on the presence of fractioned LCP1 molecules as free species in the blends.

Conclusively, in agreement with DSC and WXRD studies, and as it will be supported by FTIR and NMR studies in the following sections, the GPC results also indicate that, due to chemical interaction, the molecular weight of $P C$ is decreased during the heat treatment of the blends and contained some LCP1 moieties in its structure as a one-component species.

\subsection{FTIR Results}

The initial studies of LCP1/PC blends by FTIR technique also favor the existence of LCP1 bounded moieties by heat treatment. Despite the complexity of the FTIR vibrational spectra of these polymers, we only focus on the major vibrations which are useful in this verification. In Figures $\mathbf{8} \mathbf{a}$ and $\mathbf{8 b}$, we present the FTIR spectra of PC and LCP1 within the $400-4000 \mathrm{~cm}^{-1}$ range, respectively.

The spectrum of PC was obtained from a film whereas that of LCP1 was taken from powder in a $\mathrm{KBr}$ 
cell. The vibrational bands of interest in the $P C$ spectrum (Figure 8a) consisted of the $-\mathrm{CH}_{3}$ stretching bands at 2968, 2936, and $2973 \mathrm{~cm}^{-1}$; the $\mathrm{C}=\mathrm{O}$ singlet at $1775 \mathrm{~cm}^{-1}$, the doublets at 1603 and $1594 \mathrm{~cm}^{-1}$, as well as two other unidentified singlets at 1015 and 1080 $\mathrm{cm}^{-1}$. The vibrational bands of interest in LCP1 spectrum (Figure $\mathbf{8 b}$ ) were the broad hydroxyl group at $3457 \mathrm{~cm}^{-1}$; the symmetric and asymmetric $-\mathrm{CH}_{2}$ stretching bands at 2853 and $2930 \mathrm{~cm}^{-1}$; the aromatic $=\mathrm{C}=\mathrm{O}$ stretching at $1756 \mathrm{~cm}^{-1}$; the aliphatic $=\mathrm{C}=\mathrm{O}$ vibrations at 1735 and $1740 \mathrm{~cm}^{-1}$ and the three unidentified singlets at 1005, 1052 and $1600 \mathrm{~cm}^{-1}$.

Considering the differences between these selected vibrations of PC and LCP1, in Figure $9 a$ and $9 b$ we plotted the FTIR spectra of the soluble portions of two heat-treated LCP1/PC blends at 90/10 (Figure 9a) and $50 / 50$ (Figure 9 b) weight ratios, respectively. It should be noted that after heat treatments, the $90 / 10$ blend was soluble in $\mathrm{CH}_{2} \mathrm{Cl}_{2}$, whereas the $50 / 50$ blend provided a soluble portion and an insoluble residue consisting of around $80 \%$ of the original LCP1.

In addition to the obvious vibrations of PC, The FTIR spectra of the blends also clearly exhibit the vibrational bands of LCP1 moieties. As supported by the results of GPC and NMR (see the next section), the existence of LCP1 vibrations in these one-component samples is additional strong support for chemical bindings between PC and LCP1 components.

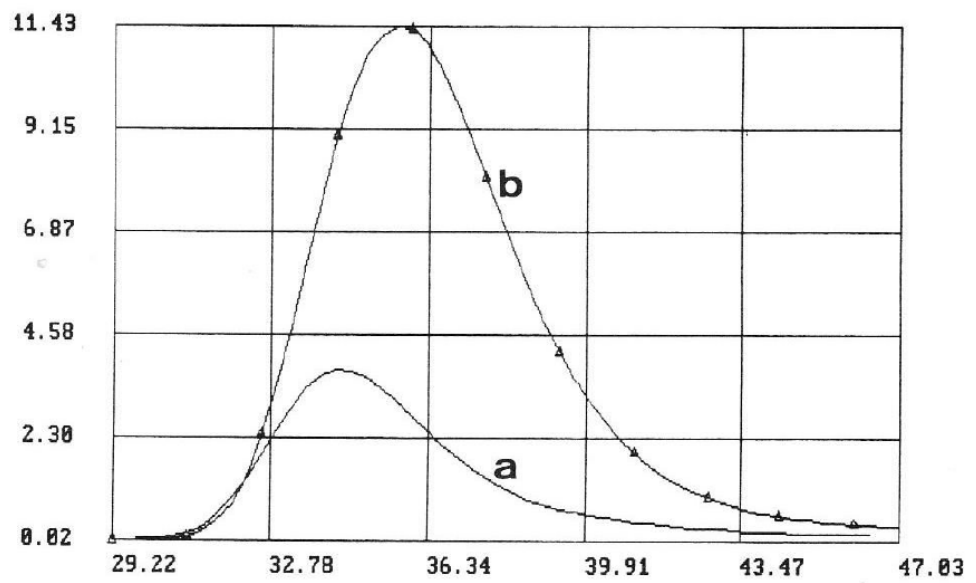

Figure 7: The GPC chromatogram in THF at $254 \mathrm{~nm}$ of a) pure PC and b) 10/90 LCP1/PC blend. The vertical axis is in the arbitrary unit and the horizontal axis is the retention time in minutes.
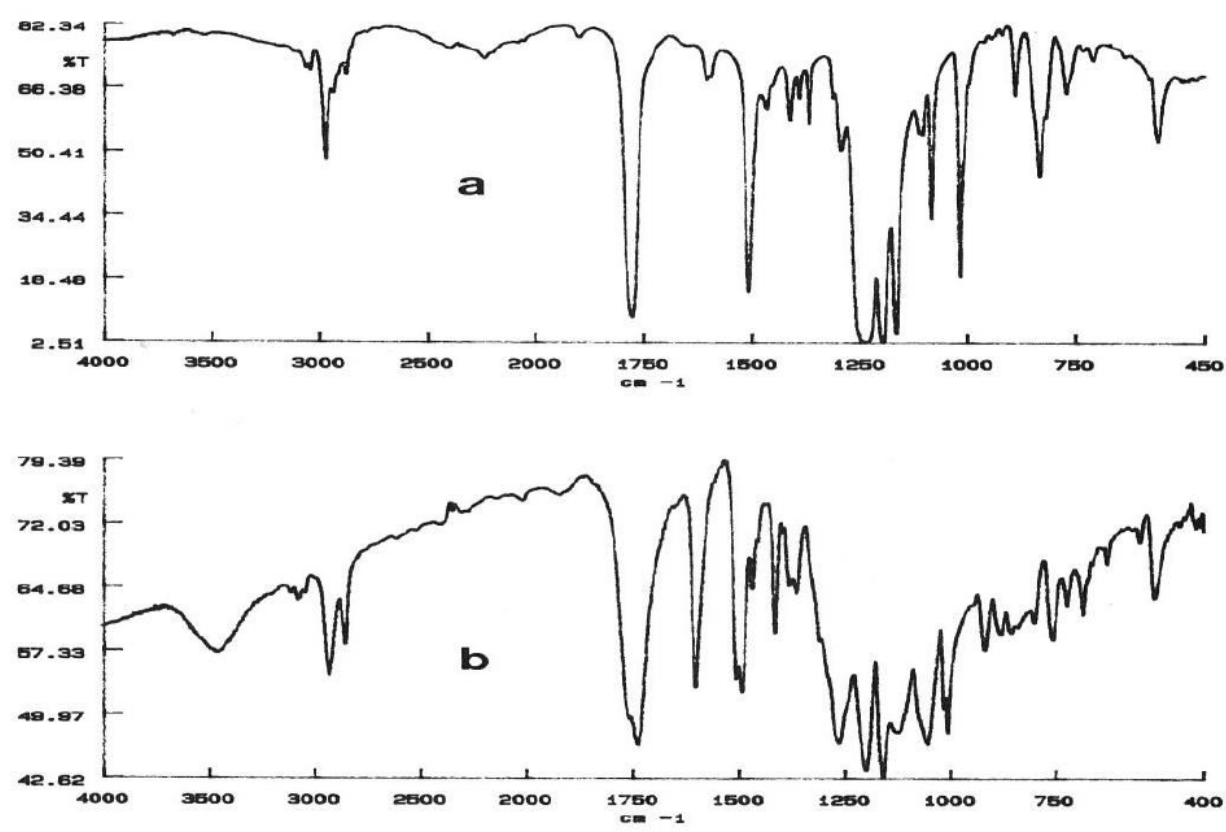

Figure 8: The room temperature absorption FTIR spectra of a) PC film and b) LCP1 powder within $400-4000 \mathrm{~cm}^{-1}$ range. 

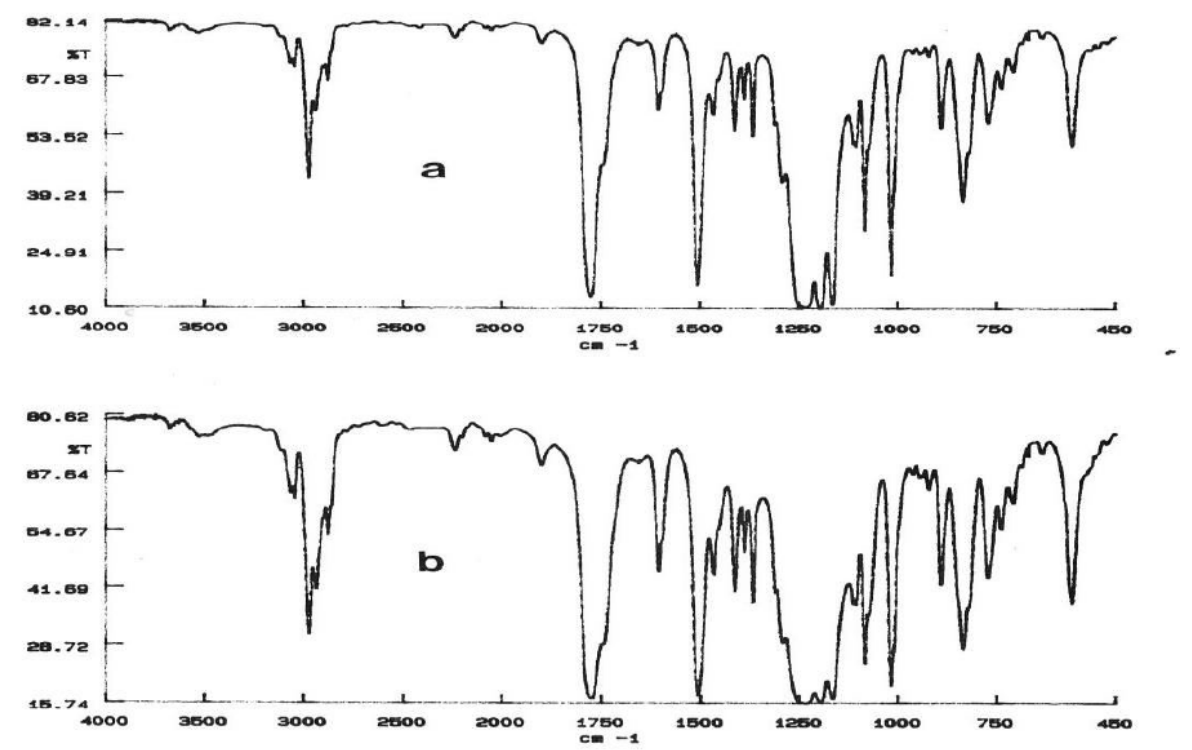

Figure 9: The room temperature absorption FTIR spectra of soluble portions of a) 10/90 and b) 50/50 LCP1/PC blends within $400-4000 \mathrm{~cm}^{-1}$ range.

Subsequently, according to Figure 9, the existence of LCP1 in LCP1/PC blends could be found in the following vibrations:

- $\quad$ Presence of hydroxyl vibration at $3450 \mathrm{~cm}^{-1}$,

- Relative intensities of 2857 and $2932 \mathrm{~cm}^{-1}$ shoulder vibrations,

- Existence of aliphatic $=\mathrm{C}=\mathrm{O}$ vibration at 1745 as a shoulder,

- Increase in relative intensity of $1603 \mathrm{~cm}^{-1}$ vibration compared to pure PC.

- $\quad$ The appearance of two shoulder signals at 1008 and $1071 \mathrm{~cm}^{-1}$.

Without further analysis of the FTIR spectra, these qualitative results are a sufficient indication of the presence of LCP1 species in the chemical structure of PC. Note that, the reported FTIR studies of heattreated blends are similar to those presented in Figure 9. However, by different heat treatments, the assigned vibrational bands could show various intensities as a result of different degrees of chemical interactions.

\subsection{NMR Results}

The pure PC and LCP1 materials and their blends were subjected to both ${ }^{1} \mathrm{H}$ and ${ }^{13} \mathrm{C}$ NMR analysis. In Figures 10a and 10b, we provide the ${ }^{1} \mathrm{H}$ NMR spectra of $P C$ and a soluble portion of 50/50 heat-treated LCP1/PC blend, respectively. The spectra of samples were obtained from their solutions in chloroform and TMS was used as an internal standard.

The peak assignments of $\mathrm{PC}$ spectrum (Figure 10a) in a strait forward, where the $-\mathrm{CH}_{3}$ protons show a singlet at $1.7 \mathrm{ppm}$ and the aromatic protons exhibit quartet centered at $7.2 \mathrm{ppm}$. In addition to these signals, in the spectrum of LCP1/PC blend (Figure 10b) also consists of other following minor signals: Two triplets at 1.4 and $2.55 \mathrm{ppm}$ of the proton resonances of aliphatic $-\mathrm{CH}_{2}$ polymer chain; two doublets at 7.0 and $7.6 \mathrm{ppm}$ are ${ }^{1} \mathrm{H}$ resonances of two types of dioxy-biphenylene protons and finally, a quartet centered at 8.3 $\mathrm{ppm}$ attributed to oxy-benzoate protons near to $=\mathrm{C}=\mathrm{O}$ group. The presence of these small resonances is an indication of the presence of bonded LCP1 moiety in the chemical structure of PC structure after heat treatment.

A similar conclusion could be achieved from ${ }^{13} \mathrm{C}$ NMR spectra of PC and LCP1/PC blends presented in Figures $11 \mathrm{a}$ and $\mathbf{1 1 b}$, respectively. In comparison with ${ }^{13} \mathrm{C}$ spectrum of PC (Figure 11a), the ${ }^{13} \mathrm{C}$ spectrum of LCP1/PC blend (Figure 11b) consists of additional 13 satellite resonances at $25,29,35,121,129,132,138$, $148,151,152,155,164$ and $172 \mathrm{ppm}$. The only difference between these signals and those of LCP1 is their appearance at the higher end of the ${ }^{13} \mathrm{C}$ spectrum. Note that, in the ${ }^{13} \mathrm{C}$ spectrum of pure $\mathrm{PC}$ the $=\mathrm{C}=\mathrm{O}$ moiety exhibits two doublet resonances at 168 and 178 $\mathrm{ppm}$, instead are shifted to 164 and $172 \mathrm{ppm}$ in the spectrum of LCP1/PC blend (see Figure 10b). Also, the absence of $P C$ 's $=C=O$ resonance signal at $157 \mathrm{ppm}$ in 


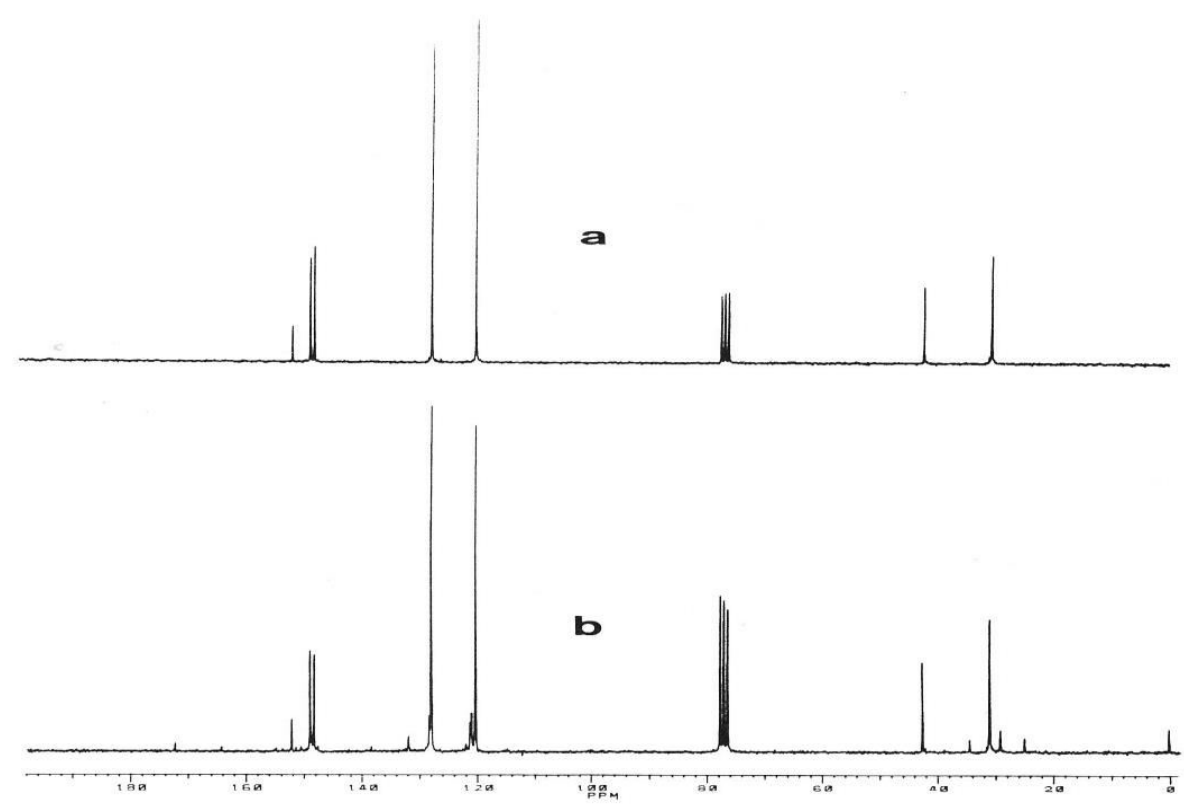

Figure 10: The ${ }^{1} \mathrm{H}$ NMR spectra of a) PC and b) $50 / 50$ heat treated $\mathrm{LCP} 1 / \mathrm{PC}$ blend in $\mathrm{CDCl}_{3}$ at room temperature.

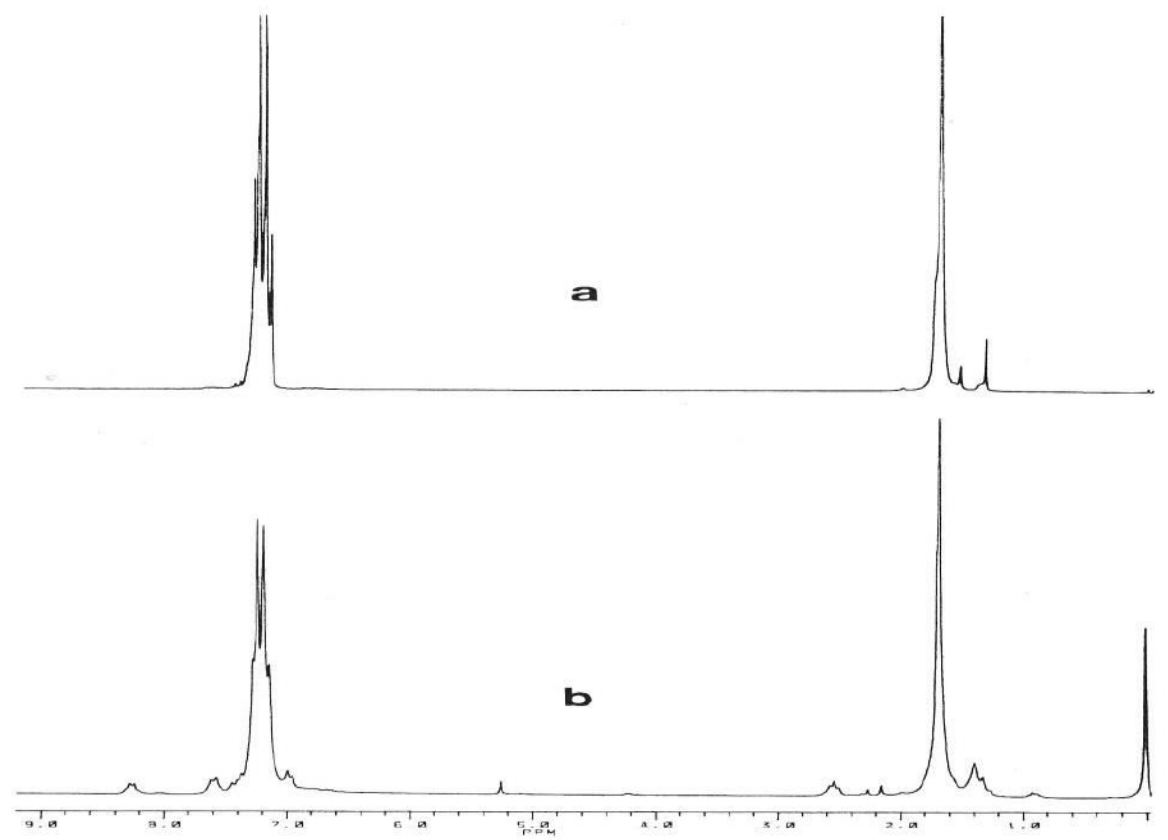

Figure 11: The ${ }^{13} \mathrm{C}$ NMR spectra of $\left.\mathbf{a}\right) \mathrm{PC}$ and $\mathbf{b}$ ) heat-treated 50/50 LCP1/PC blend in $\mathrm{CDCl}_{3}$ at room temperature.

the spectrum of LCP1/PC blend is further support of chemical reaction between PC and LCP1 components.

Therefore, in agreement with the results from other techniques, particularly with DSC, FTIR, and GPC results, we can also conclude that, during the heattreatment of the blends, a definite molecular interaction takes place between PC and LCP1 polymer chains. In such interactions, which occur at above $20 \%$ LCP1, the chemical structure and macromolecular integrity of the original PC are preserved, but the molecular weight of interacted LCP1 and PC species are smaller than that of the original PC.

Furthermore, although we do not have further information about the chemical structure of LCP1 in the blend, the present results suggest that its molecular structure has been drastically affected by heat treatment. Whatever the structural nature of the LCP1/PC blend may be, the present results indicate that it consists of one chemical species. 


\section{CONCLUSION}

We reported on the binary phase diagrams of flexible nematic LCP1 and commercial PC thermoplastic blends. After heat treatment, the blends of these two initially incompatible polymers exhibit miscibility and evidence of chemical interactions between LCP1 and PC polymer structures in their heattreated blends. The properties of heat-treated LCP1/PC blends studied with DSC, OM, WXRD, GPC, FTIR, and NMR techniques are significantly different from those of pure LCP1 and PC components, which strongly supports of the chemical interaction.

It is known that at high temperatures, polyesters can have chemical reactions with other polymers by either hydroxyl end-group reaction (alcoholysis), acid endgroup reaction (acidolysis), or by the midchain esterester interchange (transesterification) [54,55]. It is also known that, in the case of high molecular weight polymers like LCP, due to low end- group concentration, the probability of chemical reaction by transesterification is much higher than alcoholysis or acidolysis reactions [56-59]. Hence, transesterification usually dominates the reaction process in relatively high molecular weight polyesters. As transesterification in such blends continues, new compatible amorphous blends will form and in LCP/thermoplastic blends, the liquid crystalline character of the blends is lost.

It has been reported that, in heat-treated blends of $\mathrm{PC}$ and random liquid crystal co-polyester, the esterester interchange in the two polymers takes place where the bisphenol-A unit of PC first reacts with terephthalate unit and then with an oxy-benzoate unit of liquid crystal co-polyester [27-30, 40], where the miscibility increases with transesterification in the blends of PC and other polyesters with LCPs. [56, 5861]

Although in the present study of heat-treated LCP1/PC blends, the origin of a chemical reaction is likely transesterification, however, due to the lack of information on the molecular weights of the utilized LCP1 and PC, we hesitated to directly specify the transesterification and instead utilized the more general term chemical reaction throughout this study. Given the important nature of chemical reactions in LCPreinforced thermoplastic composites with either mechanism, specifically for industrial applications, it will require further in-depth and systematic future investigations on LCP composites with commercial engineering plastics.

\section{ACKNOWLEDGEMENTS}

The experimental part of this study had been carried out during the 1988-1989 period at EniRicerche, ENI Group, San Donato Milanese, (MI), Italy. Special thanks go to the POSPE team members, including $L$. Marchese, E. Montani, A. Peraio, and A. Manclossi, who carried out the experimental parts of this study.

\section{FUNDING}

This research was based on the internally funded project by EniRicerche, ENI Group, San Donato Milanese, (MI), Italy, and received no external funding.

\section{DATA AVAILABILITY STATEMENT}

The raw/processed data required to reproduce these findings cannot be shared at this time due to technical limitations.

\section{CONFLICTS OF INTEREST}

The author declares no conflict of interest. The internal funder had no role in the design of the study; in the collection, analyses, or interpretation of data; in the writing of the manuscript, or in the decision to publish the results.

\section{REFERENCES}

[1] Carfagna C, Ed., Liquid Crystalline Polymers, 1993 Pergamon Press. https://doi.org/10.1016/B978-0-08-042149-0.50011-9

[2] La Mantia, FP. Ed., Thermotropic Liquid Crystal Polymer Blends, 1995, Technomic.

[3] Isayev, Kyu AIT \& Cheng SZD, Liquid-Crystalline Polymer Systems, 1996, ACS Symp. Ser. https://doi.org/10.1021/bk-1996-0632

[4] Donald M, Windle AH \& Hanna S., Liquid Crystalline Polymers, 2006 Cambridge Univ. Press. https://doi.org/10.1017/CBO9780511616044

[5] Hull D., Introduction to Composite Materials. Cambridge University Press, Cambridge, 1987 p. 3.

[6] Evstatiev M, Fakirov S, Bechtold G and Friedrich K, Adv. Polym Technol., 2000,19, 249. https://doi.org/10.1002/1098-2329(200024)19:4<249::AIDADV2>3.0.CO;2-R

[7] 21 Chakraborty S, Sahoo NG, Jana GK and Das CK, J. Appl. Polym. Sci., 2004, 93, 711. https://doi.org/10.1002/app.20482

[8] 22 Tjong SC, Mater. Sci. Eng. Rep., 2003, 41, 1. https://doi.org/10.1002/polb.10497

[9] 23 Song $\mathrm{CH}$ and Isayev Al, Polymer, 2001, 42, 2611. https://doi.org/10.1016/S0032-3861(00)00555-3

[10] 24 Handlos AA and Baird DG, Int. Polym. Proc., 1996, 11, 82. https://doi.org/10.3139/217.960082

[11] Shibayev VP \& Byelyayev SV, Polymer Science U.S.S.R., 1990, V32 12, 2384.

https://doi.org/10.1016/0032-3950(90)90414-2

[12] Jaffe M, Journal of Statistical Physics, 1991, V62, 5-6, 985 https://doi.org/10.1007/BF01128172

[13] Shibaev VP \& Lam L, Liquid Crystalline Polymers, 1994, Springer. [14] Harper CA, Ed., Modern Plastics Handbook, 2000, ISBN 0-07026714-6. 
[15] Callister C, Materials Science and Engineering - An Introduction, 2007, V557-558.

[16] DeMeuse MT \& Jaffe M, Mol. Cryst. Liq. Cryst. Inc. Nonlin. Optics, 1988, V157, 535.

[17] DeMeuse MT \& Jaffe M, Polym. Prep., 1989, V30, 540.

[18] DeMeuse MT \& Jaffe M, Liq. Cryst. Polym., 1990, R.A. Weiss \& C.K Ober, Eds., 435.

[19] DeMeuse MT, SPE ANTEC'93, 1993, 1722 https://doi.org/10.1016/0306-3747(93)90145-4

[20] Lin YG \& Winter H H, Poly. Eng. Sci., 1992, V32, 773. https://doi.org/10.1002/pen.760321203

[21] Ding R \& Isayev AI, SPE ANTEC'93, 1993, 1176 https://doi.org/10.1016/0002-8223(93)91658-D

[22] Weiss RA, Huh W, Nicolais L, Polym. Eng. Sci., 1987, V27, 684. https://doi.org/10.1002/pen.760270913

[23] Blizard KG \& Baird DG, Polym. Eng. Sci., 1987, V27, 653. https://doi.org/10.1002/pen.760270909

[24] Nobile MR, Amendola E., Nicolais L, Acierno D, Carfagna C., Polym. Eng. Sci., 1989, V29, 244.

https://doi.org/10.1002/pen.760290406

[25] Hong SM, Kim BC, Hwang SS \& Kim KU, Polym. Eng. Sci., 1993, V33, 630 .

https://doi.org/10.1002/pen.760331008

[26] Whitehouse C; Lu XH, Gao P, Chai CK, Polym. Eng. Sci., 1997, V37, 1944. https://doi.org/10.1002/pen.11845

[27] Sun LM., Sakamoto T, Ueta S, Koga K, Takayanagi M, Polym. J., 1994, V29, 939-952.

https://doi.org/10.1295/polymi.26.939

[28] Wei K-H, Ho J-C, J Appl Polym Sci,, 1997, V63, 1527. https://doi.org/10.1002/(SICl)1097-4628(19970321)63:12<1527::AIDAPP3>3.0.CO;2-Q

[29] Ho J-C, Wei K-H, Polymer, 1999, V40, 717 https://doi.org/10.1016/S0032-3861(98)00014-7

[30] Pisitsak P, Magaraphan R, Jana SC, J. Nanomaterials, 2012, V2012, 1. https://doi.org/10.1155/2012/642080

[31] Magagnini PL, Paci M, La Mantia FP, Valenza A, Polym. Inter., 1992, V28, 4, 271.

https://doi.org/10.1002/pi.4990280405

[32] Lin Q, Ho JJ, Yee AF, Polym. Eng. \& Science, 1993, V33, N13, 23. https://doi.org/10.1002/pen.760331303

[33] Lin Q, Yee AF, Polymer, 1994, V35, N16, 3463. https://doi.org/10.1016/0032-3861(94)90909-1

[34] Brostow W, Hess†Betty M, López L , Sterzynski T, Polymer, 1996, V37, 9, 1551 https://doi.org/10.1016/0032-3861(96)83703-7

[35] Carius HE, Schönhals A, Guigner D, Sterzynski T, Macromolecules, 1996, V29, 14, 5017 https://doi.org/10.1021/ma951706u

[36] Lee HS, Jung WH, Kim WN, Polymer Bulletin, 1996, V37, 503. https://doi.org/10.1007/BF00556812

[37] Kohli A, Chung N, Weiss RA, Polymer Engineering \& Science, 1989, V29, 9, 573.

https://doi.org/10.1002/pen.760290902

[38] Singer M, Simon GP, Varley R, Polymer Engineering \& Science, 1996, V36, 8, 1038. https://doi.org/10.1002/pen.10492
[39] Lam YC, Yue CY, Yang YX, Tam KC, J. Appl. Polym. Science, 2003, V87, 2, 258.

https://doi.org/10.1002/app.11361

[40] Huang G, Chan PK, Kamal MR, Canadian J. Chem. Eng., 2003, V81, $2,243$.

https://doi.org/10.1002/cjce.5450810209

[41] Wei K-H, Jang H-C, Ho J-C, Polymer, 1997, V38, N14, 3521.

[42] Olszynski P, Kozlowski M, Kozlowska A, Materials Research Innovations, 2002, V6, 1.

https://doi.org/10.1080/14328917.2002.11784703

[43] García M, Eguiazábal JI, Nazábal J, Polymer Composites, 2004, V23(4), 592-602.

https://doi.org/10.1002/pc.10459

[44] Valera Rizo H, Vic Fernandez I, Del Agua Hernandez D, 2016, WO/2016/135671.

[45] Tyan H-L, Wei G-H, J. Polym. Sci., Part B: Polym. Phys., 1998, V36, 1959.

https://doi.org/10.1002/(SICI)1099-0488(199808)36:11<1959::AIDPOLB17>3.0.CO;2-6

[46] Kollodge JS, Porter RS, Macromolecules 1995, V28, 12, 4106 https://doi.org/10.1021/ma00116a009

[47] Tovar G, Carreau PJ, Schreiber HP, Colloids and Surfaces, 2000 V161, 1, 213

https://doi.org/10.1016/S0927-7757(99)00339-8

[48] Bum S, Ok O, Yoon KH, J. Appl. Polym. Science, 2001, V82, 11, 2799.

https://doi.org/10.1002/app.2134

[49] Yin B, Zhao Y, Yang W, Pan M, Yang M, Polymer, 2006, V47, 25, 8237-8240.

https://doi.org/10.1016/j.polymer.2006.09.044

[50] Maganini PL, Pedretti U, Perego G, Bresci B, Carrozzino S, Roggero A, 1989, US4,833,299.

[51] Magagnini PL, Bresci B, Paci M, Roggero A, Pedretti U, La Mantia FP, Rec. Adv. Chem. Eng. 1991, 28, 271. https://doi.org/10.1002/pi.4990280405

[52] La Mantia FP, Valenza A, Paci M, Magagnini PL, Pedretti U, Roggero A, Polym. Eng. Sci. 1992, 30, 13.

[53] Pazzagli F, Paci M, Magagnini P, Veracini CA, J. Appl. Polym Sci., 2000, V77, 141

https://doi.org/10.1002/(SICI)1097-4628(20000705)77:1<141::AIDAPP19>3.0.CO;2-9

[54] Kotliar AM, J. Polym. Sci., Macromol. Rev., 1981, V16, 367 https://doi.org/10.1002/pol.1981.230160106

[55] Pilati F, Marianucci E, Berti CJ, J. Appl. Polym. Sci., 1985, V30, 1267 https://doi.org/10.1002/app.1985.070300330

[56] Kimura M, Porter RS, J. Polym. Sci., Polym. Phys. Ed., 1983, V21, 367.

https://doi.org/10.1002/pol.1983.180210304

[57] Godard P, Dekoninck JM, Devlesaver V, Devaux J, J. Polym. Sci. Polym. Chem., 1986, V24, 3301. https://doi.org/10.1002/pola.1986.080241214

[58] Henrichs PM, Tribone J, Massa DJ, Hewitt JM, Macromolecules, 1988, V21, 1282 https://doi.org/10.1021/ma00183a018

[59] Laivins GV, Macromolecules, 1989, V22, 3974. https://doi.org/10.1021/ma00200a027

[60] Su KF, Wei KH, J. Appl. Polym. Sci., 1995, V56, 79. https://doi.org/10.1002/app.1995.070560111

[61] Wu L, Jang J, He J, Polymer, 2006, V 47, Issue 1, 448. https://doi.org/10.1016/i.polymer.2005.11.044

(C) 2021 H. Hakemi; Licensee Lifescience Global.

This is an open access article licensed under the terms of the Creative Commons Attribution Non-Commercial License (http://creativecommons.org/licenses/by-nc/3.0/) which permits unrestricted, non-commercial use, distribution and reproduction in any medium, provided the work is properly cited. 